\title{
Uma outra república do entretenimento
}

\section{Márcio Serelle}

Professor do Programa de Pós-Graduação em Comunicação Social da PUC-Minas

Resumo: Este artigo propõe a noção de entretenimento fraturado como modo de compreensão, em nosso meio, de determinadas narrativas midiáticas (telenovelas, reality shows, alguns filmes), que, na redução do ficcional, conformam instâncias de debate acerca de temáticas políticas, sociais e culturais, em relação direta com o circunstancial. Essa característica de nosso entretenimento, que escapa à definição do âmbito - à sua condição de mundo duplicado e autônomo, desobrigado de ensinamento - é examinada a partir da particularidade histórica de nosso processo de midiatização, marcado pela imisção social das mídias que, sem encontrar propriamente resistência da cultura letrada europeizada e na insuficiência de aparatos tradicionais asseguradores de cidadania (como, por exemplo, o sistema educacional), assumem - e/ou a elas é conferida função pedagógica.

Palavras-chave: Cultura das mídias, entretenimento, ficção, televisão brasileira

Abstract: The present article introduces the concept of shattered entertainment as to apprehend, in our field of study, certain media narratives (soap operas, reality shows and some movies) that, regarding their reduction as fiction, open space for the debate of political, social and cultural issues in direct relationship to what is circumstantial. Such aspect of our entertainment, detached from its usual definition - as being a folded and independent world, disengaged from educational attempts - is examined considering the historical specificity of our mediatization process. It was forged in the blend of the media into social life and as they did not exactly find resistance from the European-like literate culture and in the failure of traditional apparatus to grant citizenship (as, for example, the educational system), the media assume - and/or is trusted to them - a pedagogic role.

Keywords: Media culture, entertainment, fiction, Brazilian television

A ideia corrente de que a cultura midiática, como sistema interacional de referência (BRAGA, 2006), suplantou a cultura do livro (1), tornando obsoletos valores inerentes ao pensamento em linha (historicidade, rigor conceitual, humanismo), deve ser examinada, em nosso meio, a partir do seguinte traço: tivemos, desde o período colonial, no Brasil, uma literatura quase sem leitores, e que, por isso, se o didatismo dessa periodização serve à Europa e aos Estados Unidos - embora, neste, exista, também, a especificidade da virada 
para o entretenimento como gesto político - ele pouco ajuda na compreensão de nossa realidade, em que a tradição literária foi privilégio de uma pequena elite, não necessariamente econômica. No panorama para estrangeiros descrito por Antonio Candido (2000: 137), as formas escritas de expressão deixaram de funcionar como estimulantes em nossa sociedade antes mesmo de forjarem uma tradição, pois, à medida que, tardiamente (de acordo com a pauta europeia), na década de 1940, formava-se um público leitor, este era rapidamente confiscado pelos meios de comunicação de massa, que exigiam pouca "concentração espiritual" e permitiam acesso "mais fácil”, de uma audiência cada vez maior, à ficção.

O comentário de Silviano Santiago (2004) ao pensamento de Candido, visto como demasiadamente moderno ao propor a formação do cidadão exclusivamente pela via ilustrada (leitura e outras formas eruditas de arte) e, portanto, como inadequado para a compreensão da contemporaneidade, caracterizada pela crítica e falência da grande divisão (2), acaba por expor, em forma de questão, o que foi elaborado pelo autor de Literatura e sociedade: “Trata-se de repensar o que se deve entender como 'alfabetização' numa sociedade de massa que não passou pela alfabetização fonética na sua devida época e que, também por isso, perdeu a educação universitária na sua década gloriosa" (SANTIAGO, 2004: 129). Para Santiago, "[h]á de se ter menos preconceito para com as formas pop de produção artística" (idem, ibidem: 130), devendo-se evitar tomar produtos midiáticos que merecem "repúdio" pelos dispositivos que os veiculam. Santiago propõe, ao final, como forma de forçar o aprimoramento dos produtos do simulacro (na perspectiva pós-moderna horizontalizante do autor, não necessariamente inferiores às artes presenciais, de experiência in corpore), o refinamento crítico do leitor ou espectador, à guisa da media literacy inglesa, para que, por meio desse letramento contemporâneo, ele se torne um indivíduo mais consciente de seu universo cultural, em que estão projetados "tanto o telejornal como a telenovela, tanto a retransmissão de um concerto de música clássica quanto uma discussão por intelectuais numa televisão educativa" (idem, ibidem, p. 132).

A ascensão das mídias no Brasil deu-se, portanto, mais livremente e com fácil adesão (que pode ser confirmada, atualmente, no modo como grassa, em nosso meio, a comunicação digital, e como os indivíduos inserem-se, com desembaraço, nos jogos transmidiáticos (3), que articulam tevê, cinema, impresso, games, internet etc.), sem os parâmetros da cultura letrada, restrita, aqui, a uma franja europeizada. Não que o paradigma europeu não tenha exercido sobre nós certa influência, mas, com certa recorrência, como na ironia machadiana desvelada por Schwarz (2006), esse espírito educado foi, já em nossa modernidade, visto ao mesmo tempo como modelo e algo fora de esquadro, gesto empertigado inadequado à nossa "barbárie", até que, nas últimas décadas, que coincidem estatisticamente com a expansão da classe média em nosso país (29\% da população, que detêm $46 \%$ da renda nacional), o entretenimento midiático e a democracia radical parecem ter sido encampados de forma desconstrangida ou desrecalcada. Observemos, por exemplo, o fenômeno que ocorre em nossos jornais de referência, cuja linguagem aproxima-se, neste momento de esforço de reformulação ou reposicionamento de contratos de leitura, daquela antes reservada aos populares (4). 
"Schwarzenegger quer exterminar álcool brasileiro", diz-nos, como nos mostra o estudo de Viggiano (2010: 88), a primeira página de um até então tradicional jornal mineiro, com imagem em que, nos óculos escuros da imagem do Schwazenegger exterminador, não o governador, refletem o luminoso de um posto de abastecimento. A matéria, na parte interna do periódico, explica que pesquisa desenvolvida pela Universidade de Purdue resultou em relatório do governo do estado da Califórnia que aponta falhas no combustível brasileiro.

Os elementos do entretenimento tornam-se, portanto, "mapas de significado", no sentido que Hall et al. (2003) conferem à expressão, isto é, formas culturais reconhecíveis, que constituem a base de um conhecimento social compartilhado, conformando a narração jornalística e acenando com possíveis significações para os eventos. O entretenimento atua, nesse jornalismo, como uma espécie de tradução, que medeia o factual por meio de uma forma simbólica familiar aos sujeitos contemporâneos, forrando a narrativa como se fosse ele próprio uma matriz mítica de nossa sociedade.

Embora seja a midiatização processo universal, algumas particularidades dela na cultura brasileira devem ser consideradas, notadamente o modo como os empreendimentos tecnomidiáticos tomaram corpo em uma sociedade com "gritantes insuficiências em termos de níveis de renda, de acesso aos direitos trabalhistas e previdenciários, à escolaridade e à cidadania política e cultural, de parcelas numericamente expressivas da população (...)” (MICELI, 2005, p. 246). Essa imisção basilar da mídia em nossa modernidade explica, possivelmente, o aparelhamento e a eficiência de nossa indústria cultural, que não poder ser considerada mera ressonância dos estímulos produzidos nos centros capitalistas de entretenimento, bem como o caráter fraturado das ficções midiáticas - ou a insuficiência ficcional delas, como discutiremos na parte final deste artigo - que, não raro, de consciência pedagógica, servem propositadamente ao agendamento de questões públicas, que, a princípio, deveriam ser debatidas, de forma mais continuada, em outros fóruns. Sobre o primeiro aspecto, recuperemos a afirmação de Miceli, reiterada em vários de seus artigos, de que nossa experiência acabou por negar, em parte, mesmo antes da globalização, os prognósticos de relação de dependência dos países subdesenvolvidos ou em desenvolvimento em relação aos centros capitalistas, no que tange a produção industrial de bens culturais, haja vista que

A indústria cultural brasileira não apenas logrou desenvolver centros tecnologicamente avançados e sofisticados de produção destinados a um mercado interno em crescimento acelerado, mas também tem tido êxito na exportação de programas de televisão (novelas, documentários, seriados dramáticos etc.) filmes [em especial, os pornográficos para a América Latina], fascículos, livros e música popular (MICELI, 2005: 246).

Em casos mais recentes de importação de formatos televisivos, como o CQC e o Big Brother, é também sensível o modo como esses produtos são hibridizados, em nossa cultura, numa espécie de antropofagia esvaziada - pois não traz em si nenhuma atitude programática, para além da lógica do mercado -, mas que, 
ainda assim, apropria-se e traduz criativamente, para o nosso meio, programas já testados e bem sucedidos em outros países. No caso do $C Q C$ podemos ressaltar o humor e a ironia que remetem a uma genealogia do cômico em nossa mídia -Pasquim, Ernesto Varella, Casseta e Planeta; No BBB, comumente enfatiza-se a construção folhetinesca da trama como caricatura intencionada de nossa telenovela.

De certo modo, o próprio uso corrente da expressão “cultura das mídias" em nosso meio acadêmico em sentido mais próximo à concepção de Kellner que à de Santaella, convém ressaltar - implica a consciência da centralidade dos produtos do entretenimento, principalmente os televisivos, em nossa sociedade e da necessidade de abordagem crítica desses objetos. Na perspectiva moderna, porém, a expressão seria essencialmente um oximoro, pois o midiático, na visada ilustrada que prestigia obras culturais como a literatura literária, artes plásticas, música erudita etc., seria mais barbárie que cultura, sendo esta, na distinção proposta por Teixeira Coelho (2008: 20), "o que estimula o desenvolvimento humano individual e, em consequência (não o contrário) o processo social", e aquela o "que o impede, distorce e aniquila" esse mesmo desenvolvimento. No entanto, conforme explica Kellner, o termo cultura das mídias refere-se tanto à natureza comodificada dos artefatos das indústrias culturais como a seus modos de produção, distribuição e recepção, quebrando a barreira entre os campos de estudo de cultura, mídias e comunicação e chamando atenção para a interconexão entre mídias e cultura na constituição das sociedades, o que nos parece, em certa medida, pertinente para análise do contexto brasileiro. "Cultura das mídias” evita, ainda, segundo Kellner (2001: 33), termos ideológicos como "cultura de massa", que "tends to be elitist, erecting a binary opposition between high and low that is contemptuous of the 'masses' and its culture".

A noção de cultura das mídias, que delineia espaço legítimo de investigação, cujos produtos merecem ser interpretados e não descartados a priori, deve ser compreendida, porém, no contexto norte-americano, a partir da valorização dada, naquele país, ao entretenimento, historicamente tomado como gesto político democrático, de elogio ao gosto do homem ordinário, da classe trabalhadora, em contraponto à aristocracia cultural que, no início do Oitocentos, conduzia a vida artística e reforçava, por meio da tradição, a clivagem social. A campanha eleitoral para presidente dos Estados Unidos, em 1828, encenou o conflito no campo da política institucional, pelo confronto entre o general Andrew Jackson, líder proveniente das campanhas militares no Tennesse, e John Quincy Adams, intelectual, ex-professor de Havard. "When the fighter beat the writer", interpretou Gabler (1998: 28), "the symbolism was clear that a new order was aborning not only politically but, perhaps even more important, culturally". Esse antiintelectualismo, para Gabler (idem), derivou menos de uma limitação dos cidadãos que da afirmação consciente, nos Estados Unidos, da cultura popular do homem comum, que, em sua origem, antes de ser apropriada e domesticada pela classe-média, era subversiva, seja na intervenção vulgarizadora nos textos das peças teatrais e nas pinturas, estas reduzidas e vendidas como postais; na miscelânea das performances - que envolviam cantores, dançarinas, acrobatas, comediantes, mágicos - e na interação desregrada com o público, nos bares; ou na ênfase no erotismo e na pornografia. No 
entanto, apesar da evidente preferência pelo abandono "dionisíaco" do divertimento, a alfabetização e os índices de leitura de jornais e livros eram, no século XIX, relativamente elevados entre os norte-americanos, que também possuíam intimidade com os espetáculos da alta cultura (ópera e peças de Shakespeare, por exemplo) e acompanhavam os debates políticos. Logo, há, para Gabler, uma outra narrativa possível, que evita a via fácil de acusação de filistinismo, para a transformação dos Estados Unidos em uma república do entretenimento:

By the analysis, sensationalist trash was not the default culture for the intelectually impaired but rather, like the election itself, a deliberate, self-conscious expression of cultural hostility - a willful attempt to raze the elitists' high culture and destroy their authority by creating a culture the elitists would detest. In this view, trash was a choice, a choice made precisely because it seemed so antithetical to Culture and because promoting it would infuriate the aristocrats, so that there was actually a cause and effect between how much the elitists decried entertainment and how much entertainment flourished. Or, put another way, whatever else it was, mass entertainment may have begun as the democrats' revenge against the elites they despise (GABLER, 1998: 29).

Ainda que a tese de Gabler seja questionável, ao privilegiar consciência e racionalidade em um fenômeno inegavelmente marcado pelo sensível, ela, por si só, diz-nos sobre como os norte-americanos elaboram, historicamente, sua guinada para o entretenimento, que teria no cinema sua máquina formidável, pois desprovida do peso da tradição europeia. O projeto atual de revitalização de Coney Island, ilha situada ao sul de Long Island, coloca em relevo justamente a possibilidade de recuperação, para destino turístico, de seu divertimento "irresponsável” (WISNIK; LUPINACCI, 2010: 131) cujo exotismo e aberração originais, como os das feiras mundiais dos séculos XIX e XX, são nostalgicamente valorizados como aspecto democrático da norte-americanidade, soterrado pela esterilização do entretenimento à Disney. Coney Island - que com seus parques de diversão chegou a reunir diariamente, no verão, mais de um milhão de visitantes - viveu seu apogeu na passagem do século XIX para o XX, como "lugar de uma fricção tangível entre a experiência cotidiana alienante de trabalhadores urbanos e suas famílias e o alumbramento da fantasia efêmera" (idem, ibidem: 137), e o desejo por sua recuperação, hoje, indica, mais uma vez, a centralidade do entretenimento naquela cultura.

Esse entretenimento - que na raiz latina do termo entre tenere refere-se ao dispositivo de enunciação que mantém o indivíduo dentro da obra (ou produto cultural) e dentro dele mesmo, submergindo-o e, portanto, negando-o perspectiva -, foi, no século XIX, manifestação menos oposta à informação que à arte. Diferentemente do entretenimento, a arte provocaria ekstasis, ou seja, um movimento para fora, permitindo que saiamos de nós mesmos. Na comparação entre entretenimento e arte, como recupera Gabler (1998), o primeiro seria, na concepção da aristocracia cultural, convencional e do campo dos efeitos prescritos, ao arregimentar sentidos e emoções para uma resposta passiva recompensada pela diversão, induzindo reações pelo excitamento do sistema nervoso, assim como as drogas ou os brinquedos de um parque de diversões metáfora, como lembra Gabler (idem), rotineiramente usada, pela crítica, na descrição dos blockbusters 
cinematográficos da década de 1990, comparados a montanhas-russas; o segundo, inventivo, do campo das causas, envolvendo, por meio dos sentidos, mente e alma e, diferentemente da estratégia massiva do entretenimento, tratando "each view, listener or reader as an individual, eliciting unique personal response to a work" (idem, ibidem: 19).

Como reiteração do já conhecido, o entretenimento não está, por definição, voltado a ensinamentos, mas, antes, como explica Luhmann (2005: 103), "ele utiliza um conhecimento existente para separar-se dele". Esse movimento em falso caracterizaria sua "realidade", como podemos apreender da crítica de Beatriz Sarlo (2005: 169) a A vida é bela (1997), de Roberto Benigni, filme que, de acordo com ela, só na aparência abre um debate sobre as relações entre arte, história e política, quando, na verdade, trata-se, fundamentalmente, ali, da produção de ilusão. "É um filme para distrair, na acepção mais forte do termo: ele tira a atenção daquilo que quer mostrar - um campo de concentração - e conta a história de uma mitomania privada" (SARLO, 2005: 169). Nesse jogo duplicado, Sarlo conclui, o pai faz o filho acreditar que estão em gincana; o filme faz o espectador acreditar que assiste "a um drama histórico" (idem, ibidem).

Pela formulação de Luhmann (2005), é possível aproximar entretenimento e ficção, na capacidade que ambos têm de gerar realidades autônomas - não submetidas, a princípio, a coerências históricas -, de produção, pelo “como se", de um mundo entre parênteses, como na imagem conhecida de Iser. O entretenimento - e também a ficção - não é, portanto, irreal, no sentido de não existente ou, mesmo, de oposto do real, pois pressupõe objetos "de duplo lado", selecionados também da vida empírica e que facilitam a identificação e a passagem "para a realidade ficcional, o cruzamento das fronteiras” (LUHMANN, 2005: 95), que, como num jogo, a princípio, possui demarcações espácio-temporais. Diferentemente, contudo, de um certo tipo de ficção irônica e autoconsciente, o entretenimento deve "manter o autor escondido atrás do texto" (idem, ibidem: 101), apagando os mecanismos de produção para que a ilusão se estabeleça e o espectador, leitor, ouvinte, entre outros, não tenha que optar entre apreender e interpretar os efeitos poéticos do texto "ou se entregar ao entretenimento" (idem, ibidem).

O entretenimento moderno caracterizou-se, ainda, por se desenvolver em uma sociedade em que os sujeitos não são mais determinados pela origem e precisam formar sua identidade por eles mesmos, tendo sido essa mobilidade e os projetos individuais por ela provocados plasmadas pela forma do romance, como bem observou Lukács. Esse é um ponto caro a Luhmann (2005: 106-107), pois, segundo ele, o entretenimento ao invés de determinar - "Não se motiva ninguém para ajustar o próprio comportamento (isso logo iria rapidamente exigir demais de suas próprias capacidades e, como se sabe, parecer ridículo)" - oferece tipos e experiências que permitem aos sujeitos "trabalhar a própria identidade", de um modo diferente da relação como o jornalismo e a publicidade. "É evidentemente sedutor experimentar em si mesmo realidades virtuais ao menos numa fantasia que se pode interromper a qualquer momento", (idem, ibidem: 105) conclui. 
A teoria do entretenimento, principalmente naquilo que diz sobre a irresponsabilidade do divertimento - de que Coney Island é paradigma -, desobrigado de função pedagógica, não descreve bem determinados produtos de nossa cultura midiática, pois o papel assumido por parte significativa dela, na vacância de uma tradição de formas clássicas de reivindicação na cena pública, é o de instauração de uma ágora em que são agendados, para discussão ligeira, substituídas ao ritmo das narrativas que as engendram, temáticas sociais, políticas e culturais, o que Ribeiro (2005: 135) definiu como uma "troca de papéis" com o jornalismo, este cada vez mais ficcional. De modo semelhante, Lopes (2010: 26) percebe nessa combinação entre melodrama e narrativa documental o paradoxo que "tipifica" a telenovela brasileira, o "de se 'ver' o Brasil mais nessa narrativa ficcional do que no telejornal”. A passagem do texto midiático ao contexto referida aqui não resulta de um movimento de análise sociológica aplicada aos produtos, mas, antes, numa primeira instância, de um gesto consciente de ficções que assumem para si essa função - Lopes (idem) denomina-o "ação pedagógica deliberada" -, embora, de forma ambígua, seus criadores evitem, ao mesmo tempo, a noção da educação pelo entretenimento. Uma autora de telenovelas, Glória Perez, que reivindica o pioneirismo de "introduzir a realidade na novela" (PEREZ apud BERNARDO; LOPES, 2009: 123), ao inserir, em Carmen, uma campanha de conscientização sobre a aids, que levou ao folhetim o sociólogo Betinho no papel dele mesmo, formula, assim, sua estratégia de "merchandising social":

\begin{abstract}
Para se tornar uma campanha, o tema precisa ter alcance, precisa ser capaz de suscitar debate. E também é preciso que esse debate possa resultar em benefícios concretos para a sociedade ou para o grupo social a que o tema se refere. Em $O$ clone, por exemplo, falei dos dependentes químicos, criando uma personagem que vivia esse drama e o núcleo familiar que sofria as consequências de sua dependência. Até então, como a maioria das pessoas, eu conhecia os dependentes químicos através dos relatos da polícia, dos psicólogos, dos terapeutas. E o que me interessava era saber como eles próprios enxergavam sua condição. Minhas campanhas partem do princípio de que é preciso dar voz às pessoas que não estão encontrando espaço para se expressar, e deixar que elas próprias se apresentem ao público, sem intermediários (PEREZ apud BERNARDO; LOPES, 2009: 125).
\end{abstract}

Há, nessa declaração, dois pontos que merecem ser analisados: primeiro, a noção de que a telenovela possa permitir a expressão dos próprios indivíduos, "sem intermediários", o que implica uma relação ingênua com o aparato midiático, pois o "dar voz" é sempre, em última instância, uma concessão, uma forma de mediação e enquadramento de uma fala, de uma personagem, que é sempre colocada em cena e em enredo, o que não pode, portanto, configurar ato transparente, sem intervenções, como quer a autora; segundo, a busca por "benefícios concretos para a sociedade ou para o grupo social", o que reitera a condição de entretenimento que quer reverberar funcionalmente na sociedade. Nessa esteira, Perez inseriu uma série de temas científicos, geralmente provocadores de discussão ética, e referentes à saúde pública, tais como, transplantes de órgãos, clonagem humana, inseminação artificial, esquizofrenia.

O autor de telenovelas Manoel Carlos (apud BERNARDO; LOPES, 2009: 192) diz também não abrir mão de inserir, em suas narrativas, como contraponto ao merchandising comercial, temas e comportamentos 
“que possam motivar o público, levando-o a exercer a generosidade”, embora consciente de que esse exercício míngua após o término do folhetim. Entre esses temas, incluem-se doação de medula, síndrome de Down, câncer de mama, alcoolismo, violência doméstica, preconceito racial, maus-tratos a idosos. "Longe de mim achar que novela é tão somente entretenimento. Seria dar pouco valor a um trabalho que me consome tanto tempo e exige tanto sacrifício (idem, ibidem)".

O merchandising social, prática, segundo Perez, institucionalizada no folhetim televisivo, faz com que a compreensão acerca do produto ficcional por parte dos autores seja ambígua: de um lado, a mímesis permanece genérica - isto é, voltada à imitação de elementos clássicos constituintes do folhetim, tais como o uso do duplo, das reviravoltas afetivas de comédia romântica, o whodunit, trocas de filhos, ascensão social pelo amor; de outro, o compromisso social que leva a um declínio da ficção. Não se trata, pois, de um realismo, pelo menos na sua concepção histórica (embora escritores realistas como Dickens, Balzac e Flaubert sejam os mais citados), mas o de jogo entre verossimilhança e veracidade, afirmado pelo caráter comumente blindado dos testemunhos - como aqueles que encerraram Viver a vida, de Manoel Carlos. Esses mesmos autores que afirmam a importância social da telenovela são, contraditoriamente, categóricos na assunção dos aspectos fantasiosos de suas ficções: "Novela é diversão, entretenimento. Só isso", diz Perez (apud BERNARDO; LOPES, 2009: 125), "Não me propus a educar”, diz Manoel Carlos (apud BERNARDO; LOPES, 2009: 193).

Nos programas televisivos em que o entretenimento-jogo aparece mesclado à exposição midiática do sujeito, de que o Big Brother Brasil é exemplo mais longevo, não raro tensões internas, que emergiram do confinamento, por meio do choque, previamente planejado pela produção, entre os tipos ali colocados, servem também a debates, embora esses nada têm “a ver com os mecanismos clássicos da cidadania, que implicam participação coletiva na cena pública com o objetivo de influir sobre o controle social: mandatos parlamentares, vigilância sobre o orçamento etc.” (SODRÉ, 2010, s.p.). Novamente, o caráter ficcional desses programas é insuficiente - um aspecto do próprio gênero reality show, sem dúvida -, pois, se por um lado, afirma-se, por exemplo, que seu enredo se dá por meio de construção de personagens, por outro, os participantes reivindicam o não jogo, a exposição de um sujeito verdadeiro - como se este existisse, assim, sem qualquer instabilidade - como estratégia de persuasão, prova de merecimento do prêmio ou mesmo chamamento de vitrina. Nisso, o programa acaba por sugerir que há em seu microcosmo amostragem de nossos valores que merece ser discutida para além do entretenimento, instaurando sensação de tomada de partido por meio de votação:

É natural que os 154 milhões de votantes do $B B B 10$ possam sentir-se como sujeitos que exercem democrática e comodamente, de dentro de suas casas, uma livre opção: isso ou aquilo, fulano ou fulana, homossexual ou homofóbico. A tecnologia digital amplia em muitos graus a mais a velha intimidade à distância propiciada pela telenovela. De mouse em punho, o espectador define-se de certo modo como o público da arena romana que decidia sobre vida ou morte do gladiador derrotado (SODRÉ, 2010, s.p.) 
O movimento do entretenimento ao debate de questões sociais - para Lopes (2010), no caso da telenovela, um recurso comunicativo - é perceptível, ainda, em nossa ficção cinematográfica - ver, como exemplo, Cidade de Deus, Tropa de Elite ou mesmo O invasor - o que contribui para nossa hipótese de que esse é, de modo amplo, um caráter de parte significativa de nosso entretenimento ou, pelo menos, diz tanto de uma função que este tem tomado para si em nosso meio cultural como de uma disposição de leitura “referencial” por parte da crítica e do público. Se os dois primeiros filmes são adaptações de relatos de forte traço documental - embora o autor de Cidade de Deus, Paulo Lins, tenha reivindicado, de forma veemente, porém inútil, a autonomia romanesca de seu livro -, com remissões a pessoas reais, como no caso das fotografias mostradas ao fim do filme de Fernando Meireles, $O$ invasor, de Beto Brant, partiu de argumento fictício de Marçal Aquino, o que não impediu, como expõe Nagib (2006:159), que parte significativa da crítica confirmasse nele "o caráter revelatório de uma situação nacional”. A redução do ficcional em detrimento daquilo que possa ser lido, na via imediata, como documento de circunstância não é, evidentemente, resultante apenas de um modo de olhar, de espectação, mas, por vezes, também de um discurso articulado pelo criador, que coloca em foco mais o enunciado que a enunciação, mais o que é ali mediado, como denúncia, que a mediação. Na crítica a Tropa de elite, por exemplo, Inácio Araújo (2009: 4) refere-se ao esvaziamento ficcional de um filme, que deseja ser tese:

Ora, quando falou à TV, o diretor José Padilha teorizou longamente sobre polícia e crime. Quase não falou de cinema, que também precisa de ideias. Uma delas: em cinema não existe sangue, existe vermelho (Jean-Luc Godard). Em "Tropa de Elite" há muito mais sangue que vermelho. Por isso é um fenômeno sociológico, nunca será um grande filme.

Os exemplos citados aqui - a telenovela, o reality show, o cinema - embora bastante distintos entre si, convergem em um ponto: a noção, em nosso contexto, do entretenimento fraturado, insuficientemente ficcional ou de caráter híbrido (mas distante daquilo precariamente caracterizado como infotenimento, que não está propriamente em questão aqui), que parece, à primeira vista, negar justamente o que lhe define: a situação de mundo colocado entre parênteses, suspenso. Feita a distinção, este artigo encerra com uma questão acerca desse caminho encontrado em nossa cultura midiática: se ele não é, na verdade, menos uma maneira de operar cidadania que um a meio caminho, pouco satisfatório, entre a autonomia ficcional, fantasiosa do entretenimento, em sua capacidade formadora e de apreensão de identidades, justamente pelo descomprometimento na experimentação, e, retomando Sodré (2010), as formas clássicas de reivindicação e debate, que não devem ser ligeiras, intermitentes ou mesmo ilusórias, como nos diz Sarlo (2005) sobre o movimento em falso de A vida é bela. Stanley Cavell (1979: 40) escreveu sobre o cinema que seu modo mágico de representar não reside no ato de nos apresentar o mundo pela imagem técnica, mas na forma como os filmes nos permitem ver sem sermos vistos: “This is not a wish of power over creation (as Pygmalion's 
was), but a wish not to need power, not to have to bear its burdens". E isso, talvez, não seja pouco para o entretenimento.

\section{Referências bibliográficas}

ARAÚJO, Inácio. "Tropa de elite é um filme ingênuo". Folha de S. Paulo. São Paulo, 08 de março de 2009. Ilustrada. p.4

BERNARDO, André; LOPES, Cíntia. A seguir, cenas do próximo capitulo. São Paulo: Panda Books, 2009.

BRAGA, José Luiz . Sobre mediatização como processo interacional de referência. In: $15^{\circ}$ Encontro Anual da Compós, 2006, Bauru/SP. Anais. XV Encontro Anual da Compós - Associação Nacional dos Programas de Pós-Graduação em Comunicação, 2006. v. 1. p. 1-16.

CANCLINI, Néstor García. Latino-americanos à procura de um lugar neste século. São Paulo: Iluminuras. 2008.

CANDIDO, Antonio. Literatura e sociedade. 8a. ed. São Paulo: T. A. Queiroz Editor, 2000.

CAVELL, Stanley. The world viewed. Cambridge, Massachusetts; London: Havard University Press, 1979.

COELHO, Teixeira. A cultura e seu contrário. São Paulo: Iluminuras: Itaú Cultural, 2008.

DEJAVITE, Fábia Angélica. “Infotenimento nos impressos centenários brasileiros”. Estudos de Jornalismo e Midia. Ano V - n. 1. p. 37-48 Jan./Jun. 2008.

GABLER, Neal. Life, the movie. New York: Radom House, 1998.

HALL, Stuart et alli. A produção social das notícias: o mugging nos media. In: TRAQUINA, Nelson (org.). Jornalismo: questões, teorias e estórias. Lisboa: Vega, 2003. p. 224-228.

HUYSSEN, Andreas. After the great divide. Bloomington, Indianapolis: Indiana University Press, 1986.

JENKINS, Henry. Cultura da convergência. Trad. Susana Alexandria. São Paulo: Aleph, 2008.

KELLNER, Douglas. Media culture. London and New York: Routledge, 2001. p. 15-92.

LOPES, Maria Immacolata Vassalo. Telenovela como recurso comunicativo. Matrizes. Revista do Programa de Pós-Graduação em Ciências da Comunicação da Universidade de São Paulo - Ano 3, no.1 (ago/dez, 2009) - São Paulo: ECA/USP/PAULUS: 2009. p. 21-43.

LUHMANN, Niklas. A realidade dos meios de comunicação. Trad. Ciro Marcondes Filho. São Paulo: Paulus, 2005.

MICELI, Sérgio. A noite da madrinha. São Paulo: Companhia das Letras, 2005.

NAGIB, Lúcia. A utopia no cinema brasileiro. São Paulo: Cosac Naif, 2006.

RIBEIRO, Renato Janine. A política dos costumes. In: NOVAES, Adauto. Muito além do espetáculo. São Paulo: Senac, 2005. p. 128-143.

SANTIAGO, Silviano. O cosmopolitismo do pobre. Belo Horizonte: Ed. UFMG, 2004. 
SARLO, Beatriz. A família das vítimas. In: SARLO, Beatriz. Tempo presente. Trad. Luís Carlos Cabral, Rio de Janeiro: José Olympio, 2005. p. 167-169.

SCHWARZ, Roberto. "Leituras em competição”. Novos Estudos Cebrap, 75, p. 61-79, 2006.

SODRÉ, Muniz. "O triunfo estatístico do Banal”. Observatório da imprensa. Disponível em: www.observatoriodaimprensa.com.br/artigos.asp?cod=584TVQ001. Acesso em 12 de abril de 2010.

VIGGIANO, Mario Francisco Ianni. Entre o “interesse público” e o “interesse do público”: um estudo dos dispositivos de enunciação do atual contrato de leitura do jornal Estado de Minas. Belo Horizonte: PUC Minas, 2010. Dissertação de mestrado.

WISNIK, Guilherme; LUPINACCI, Heloisa. "Coney Island e o divertimento irresponsável”. Serrote. São Paulo: Instituto Moreira Sales, março de 2010. p. 131-149.

\section{Notas}

(1) Ver, além do próprio Braga, Douglas Kellner (2001: 35), em Media culture: “The term 'media culture' also has the advantage of signifying that our culture is a media culture, that the media have colonized culture, that they are the primary vehicle for the distribution and dissemination of culture, that the mass media of communications have supplanted previous modes of culture like the book or spoken word, that we live in a world in which media dominate leisure and culture".

(2) A referência aqui é à obra After the great divide, de Andreas Huyssen (1986). O discurso da grande divisão, dominante na virada do século XIX para o XX e logo após a Segunda Guerra Mundial, é aquele que, de acordo com Huyssen, insiste, categoricamente, na clivagem entre arte elevada e cultura de massa.

(3) Henry Jenkins (2008: 135), em Cultura da convergência, define a narrativa transmidiática como "aquela que se desenrola através de múltiplos suportes midiáticos, com cada novo texto contribuindo de maneira distinta e valiosa para o todo". Estratégia sinérgica dos mercados culturais, esse tipo de narrativa pode ser exemplificada, no Brasil, nas edições mais recentes do Big Brother, que envolveram, principalmente, televisão e internet no desenvolvimento da franquia.

(4) Ver, sobre esse assunto, o artigo de Dejavite (2008), "Infotenimento nos impressos centenários brasileiros". 